\title{
Risk of predation to fish larvae in the presence of alternative prey: effects of prey size and number
}

\author{
Vytenis Gotceitas, Joseph A. Brown \\ Ocean Sciences Centre, Memorial University of Newfoundland, St. John's, Newfoundland, Canada A1C 5S7
}

\begin{abstract}
Studies examining the effects of alternative prey on the risk of predation to fish larvae have found a reduced risk to larvae, but only when in the presence of a relatively high number of alternative prey. However, all studies using zooplankton as alternative prey have used zooplankters smaller in body size than the fish larvae. In this study, we provided three-spined stickleback Gasterosteus aculeatus with the opportunity to forage on 5 to $7 \mathrm{~d}$ old cod larvae Gadus morhua, presented alone and in the presence of alternative prey of different sizes and numbers relative to that of the larvae. In one experiment, larvae were presented with an equal number of Artemia salina smaller, equal and larger in body size than the cod larvae. In a second experiment cod larvae were presented in the presence of a naturally co-occurring zooplankter of equal size, adult Calanus finmarchicus. Larvae were presented at ratios of larvae to Calanus of $1: 1,3: 1$ and 5.6:1. In both experiments, the presence of alternative prey of equal or larger size significantly increased the latency (in seconds) until a cod larva was captured and decreased the overall proportion of cod larvae captured. In the second experiment, this was true even at a ratio of larvae to copepods of $3: 1$. Protection to the larvae appeared to be the result of selection by the predator of the alternative prey. Results are discussed in light of existing ideas on larval size and predation risk, and larval survival with respect to temporal and spatial overlap between larvae and zooplankton.
\end{abstract}

\section{INTRODUCTION}

Prey selection and foraging success of visually feeding planktivorous fishes have been shown to be influenced by a number of factors, including characteristics of the prey such as body size (Werner \& Hall 1974, O'Brien et al. 1985, Pepin et al. 1988), pigmentation (O'Brien 1979) and evasiveness (Vinyard 1980, Coughlin \& Strickler 1990), as well as the presence of alternative prey (O'Brien 1979, Vinyard 1980, Visser 1982, O'Brien et al. 1985). For example, numerous studies investigating factors influencing the composition of freshwater zooplankton communities have shown selection for larger-bodied zooplankton by planktivorous fish (Brooks \& Dodson 1965, Zaret \& Kerfoot 1975 , O'Brien et al. 1976, O'Brien 1979). The outcome of such selection is a significant reduction, or even elimination, of the larger species of zooplankton from these communities. As a result of such size-related predation, protection from predators to the smaller-bodied zooplankton can be viewed as the interplay of both smaller body size and the presence of larger-bodied species as alternative prey.

Predation is considered a major source of mortality in fish larvae (Hunter 1981, 1984, Bailey \& Houde 1989). Although both invertebrate and vertebrate predators are known to include fish larvae in their diet, vertebrate predators such as planktivorous fishes have been shown to have the greatest impact on larval fish mortality (Fuiman \& Gamble 1988, Litvak \& Leggett 1992, Pepin et al. 1992). As has been demonstrated for zooplankton, predation risk to fish larvae appears to be influenced by both body size (Litvak \& Leggett 1992, Pepin et al. 1992) and the presence of alternative prey (Bailey \& Yen 1983, Pepin 1987). For example, several studies have found that the presence of alternative prey (i.e. zooplankton) does reduce the risk of predation to fish larvae (Kean-Howie et al. 1988, Margulies 1990) from visually foraging planktivorous fish. However, all these studies presented the predator with alternative prey which were smaller in body size than the larvae. Under these conditions, 
protection from predation to the larvae occurred only when a high density of the alternative prey, relative to that of the larvae, was present. As a result, such protection has been attributed to a passive process, whereby at high densities the alternative prey 'interfere' with the predator's foraging activities (e.g. searching behaviour), rather than an active process in which the predator selects one prey type over the other(s). Although fish larvae tend to be among the larger-bodied organisms in the zooplankton community, zooplankton of similar, or larger, body size can co-occur with the larvae. Given the well documented influence of prey body size on prey selection by planktivores it would appear that the presence of alternative prey of equal or larger size than the fish larvae could provide protection from predation to the later. However, to date, no study has examined the effects of zooplankton body size on predation risk in larval fishes.

Three-spined sticklebacks Gasterosteus aculeatus are generalist, visually feeding, planktivores which are known to include fish larvae in their diet (Lemmetyinen \& Mankki 1975, Wootton 1984, Delbeck \& Williams 1988). In this study we first presented sticklebacks with the opportunity to forage on Atlantic cod Gadus morhua larvae in the absence or presence of an equal number of an alternative prey, brine shrimp Artemia salina, which were smaller, equal or larger in body size than the cod larvae. The purpose of this experiment was to investigate the effects of alternative prey size on predation risk to fish larvae.

A study of prey choice by planktivores, or one examining the risk of predation to their prey, is logistically very difficult in the field. Typically any such attempt is limited to the analysis of predator gut content or a temporal sampling of the composition of the zooplankton community, respectively. Therefore, in an attempt to mimic a more natural scenario we conducted a second experiment in which we presented stickleback with a choice between cod larvae and a naturally co-occurring zooplankter of approximately equal size as the larvae, adults of the copepod Calanus finmarchicus. In this second experiment, larvae and copepods were presented both at equal and different relative abundances to also look at the effects of alternative prey number on the risk of predation to the larvae.

Finally, the availability and maintenance of wild zooplankton under laboratory conditions can be prohibitive. Therefore, we compared the results from our experiments with Calanus finmarchicus to those with Artemia salina in order to assess the validity of using an easily obtained, and maintained, organism as a representative zooplankter in future research examining the effects of alternative prey on predation risk in fish larvae.

\section{MATERIALS AND METHODS}

Experimental animals. Cod larvae were reared in ambient seawater from eggs collected from a laboratory broodstock. All larvae used in experiments were 5 to $7 \mathrm{~d}$ post-hatch and similar in size (mean length \pm $1 \mathrm{SE}=4.4 \pm 0.13 \mathrm{~mm}$ ), to eliminate effects due to larval age and size on risk to predation (Litvak \& Leggett 1992, Pepin et al. 1992).

Artemia salina (hereafter Artemia) were reared in the laboratory from commercially available eggs (Argent Chemical Laboratories, 'Argentemia'). Adult Calanus finmarchicus (hereafter Calanus) were collected from the field using a plankton net $(110 \mu \mathrm{m}$ mesh). In the laboratory, copepods were housed in tanks $(34 \times 34 \times 52 \mathrm{~cm})$ supplied with a flow of ambient seawater. Copepods were used in experiments within a week of capture. Copepods with ripe ovaries were not used, as this might serve to attract the predator.

Three-spined sticklebacks, ranging in size from 5.9 to $7.3 \mathrm{~cm}$ standard length (SL), were collected in the field using a beach seine $\left(30 \times 1.5 \mathrm{~m}, 0.5 \mathrm{~cm}^{2}\right.$ mesh size). Fish were brought back to the laboratory where they were housed in a communal tank $(34 \times 34 \times 52 \mathrm{~cm})$ supplied with ambient seawater until needed. Fish were held in the laboratory for at least 1 mo to allow for a period of acclimation. When not involved in an experiment, fish were fed frozen plankton once a day.

Experimental apparatus. Experiments were conducted in 6 glass tanks $(50 \times 25 \times 30 \mathrm{~cm})$ housed in a wet-bench supplied with ambient seawater. The wetbench was enclosed by an opaque black plastic curtain to eliminate outside disturbances. Each tank was enclosed on 3 sides by an opaque white plexiglas barrier, leaving one of the large $(50 \times 30 \mathrm{~cm})$ sides open for observation. This was done to eliminate any visual stimulation of fish among tanks.

Each experimental tank was divided into 3 compartments by opaque grey plexiglas barriers, 2 predator housing compartments $(12 \times 12 \times 30 \mathrm{~cm})$ both situated at the same end of the tank, and a common area $(38 \times$ $25 \times 30 \mathrm{~cm}$ ) in which experiments were conducted. Each predator housing compartment was equipped with a sliding door $(8 \times 20 \mathrm{~cm})$ to allow access for the predator into the common 'experimental area' of the tank. Opaque barriers were used to provide visual isolation from the other fish and the experimental area.

Experimental design. Prior to using sticklebacks in the experiments, fish had to be trained to exit their compartment and enter the experimental area to feed once the door to their compartment was opened. This was done by opening the door to a stickleback's compartment and then offering it food (i.e. frozen plankton) in the experimental area. Fish were considered ready for use in experiments once they readily entered the exper- 
imental area (i.e. within 5 s) to feed when the door to their compartment was opened. Finally, prior to testing, fish were exposed to the various prey types, one prey type at a time, to be used in the experiment. This was to facilitate subsequent recognition of these as prey/food items by the fish. So as not to bias foraging by the sticklebacks due to any order-of-presentation effects, the order of prey type presented was assigned randomly among fish. Experiments began once both prey types were readily consumed by all fish.

Experiments consisted of introducing a predetermined number of prey into the experimental section of the tank and then allowing a stickleback access to the experimental area for a 2 min foraging bout. Only 1 stickleback was present in the experimental area at any one time. A 2 min foraging bout was used based on preliminary observations indicating that at the prey levels used, sticklebacks were still actively foraging at the end of the $2 \mathrm{~min}$. Following the $2 \mathrm{~min}$ foraging bout, the stickleback was coaxed back into its compartment and all remaining prey were removed. Individual fish were used in only 1 experimental trial per day. All experiments were conducted at the same time of day (13:00 to 15:00 h), and all fish were fed once a day at $16: 00 \mathrm{~h}$.

Expt 1. Cod larvae and Artemia salina: This experiment was designed to investigate whether the relative size of an alternative prey has any effect on the risk of predation to cod larvae. Prior to experiments in which a mixture of prey was presented to the sticklebacks (see below), the length of 10 of each prey type was measured using a dissecting microscope equipped with an eyepiece micrometer. The mean size of each prey type was then compared ( $t$-test) to ensure the appropriate size composition of prey was present (see the third, fourth and fifth treatments below). In this experiment each stickleback was exposed to 5 prey 'treatments': (1) 10 cod larvae presented alone (Treatment 10c); (2) 20 cod larvae presented alone (Treatment 20c); (3) a mixture of 10 cod larvae and 10 Artemia which were significantly smaller $(t=6.56$, $\mathrm{df}=18, \mathrm{p}=0.0001$, mean length $\pm 1 \mathrm{SE}=3.3 \pm$ $0.15 \mathrm{~mm}$ ) than the larvae (Treatment $10 \mathrm{c}>10 \mathrm{~A}$ ); (4) a mixture of 10 cod larvae and 10 Artemia which were the same $(t=0.37, \mathrm{df}=18, \mathrm{p}=0.71$; mean length $=4.5 \pm$ $0.16 \mathrm{~mm}$ ) size as the cod larvae (Treatment $10 \mathrm{c}=10 \mathrm{~A}$ ); and (5) a mixture of 10 cod larvae and 10 Artemia which were significantly larger $(t=15.39, \mathrm{df}=18$, $p=0.0001$, mean length $=7.8 \pm 0.16 \mathrm{~mm}$ ) than the larvae (Treatment $10 c<10 \mathrm{~A}$ ). Only one treatment was presented on any one day, determined by the availability of cod larvae and Artemia of the required size.

Treatments involving 10 and 20 cod larvae presented alone were conducted to control for possible differences in the predator's response towards cod larvae as prey when only 10 larvae were present as in the mixture treatments and/or the presence of a total of 20 prey items. Two sticklebacks died prior to the end of Expt 1. As the cause of death was unknown, data collected from these fish prior to their loss was discarded, reducing the number of test fish included in the analyses to 10 .

Expt 2. Cod larvae and adult Calanus finmarchicus: The purpose of this experiment was 2-fold, first to investigate the influence of the presence of a naturally co-occurring zooplankter of equal size as the cod larvae, and secondly to examine the effects of varying the number of this alternative prey relative to that of the cod larvae, on the risk of predation to the larvae. Prior to conducting the experiments, a sample of 10 cod larvae and 10 Calanus were measured as in the previous experiment, and mean body length was compared ( $t$ test). Calanus body length was measured from the anterior of the metasome to the posterior end of the urosome, excluding the caudal setae. There was no significant ( $t=0.98, \mathrm{df}=18, \mathrm{p}=0.34$ ) difference in the mean length of cod larvae (mean $\pm 1 \mathrm{SE}, 4.4 \pm 0.13 \mathrm{~mm}$ ) and the adult Calanus $(4.8 \pm 0.41 \mathrm{~mm})$ that were used.

Sticklebacks were again exposed to Treatments $10 \mathrm{C}$ \& $20 \mathrm{c}$ as in Expt 1, along with the following 4 treatments: (1) 15 cod larvae presented alone (Treatment 15c); (2) a mixture of 10 cod larvae and 10 Calanus (Treatment 10c:10C); (3) a mixture of 15 cod larvae and 5 Calanus (Treatment $15 \mathrm{c}: 05 \mathrm{C}$ ); and (4) a mixture of 17 cod larvae and 3 Calanus (Treatment 17c:03C). Experiments presenting cod larvae alone were conducted for identical reasons as in Expt 1.

At the time Calanus began to appear in our plankton collection, only 6 fish were available for testing due to a failure in the water system in the laboratory. These 6 fish were used in tests of Treatments $10 \mathrm{c} \& 20 \mathrm{c}$, while an additional 6 fish were trained. As a result, all other treatments in Expt 2 were presented to 12 fish.

Data collection and analysis. All data were collected by an observer seated inside the curtain surrounding the wet-bench in front of the uncovered side of each tank, using an event recorder. The following data were collected for each treatment in both Expts 1 \& 2 .

Latency (s) until the first cod larva was captured: This was measured from the time the fish entered the experimental section of the tank. Mean latency for the different treatments was compared among treatments within Expts $1 \& 2$ using Analysis of Variance (GLM Procedure; SAS 1988). We also compared the influence of the 2 alternate prey types on latency until the first cod larva was captured by comparing mean latency among Treatments 10c, 20c (Expts $1 \& 2$ ), 10c=10A (Expt 1) \& 10c:10C (Expt 2). The latter 2 treatments were chosen as these represent conditions where Artemia and Calanus were equal in size and abun- 
dance to the cod larvae tested. Data were normalized using a $\log _{10}$ transformation. Use of the same fish among treatments was corrected for by using fish as a blocking variable in the analyses (Montgomery 1991).

Proportion of cod larvae captured by the predator: Mean proportion of cod larvae captured in the different treatments was compared among treatments within Expts 1 \& 2 using Analysis of Variance (GLM Procedure; SAS 1988). We also compared the influence of the 2 alternate prey types on the proportion of cod larvae captured by comparing mean proportion of cod larvae captured in Treatments 10c, 20c (Expts 1 \& 2), $10 \mathrm{c}=10 \mathrm{~A}$ (Expt 1) \& 10c:10C (Expt 2). The latter 2 treatments were chosen as these represent conditions where Artemia and Calanus were equal in size and abundance to the cod larvae tested. Data were arcsine transformed for normality. Use of the same fish among treatments was corrected for by using fish as a blocking variable in the analyses.

Ordered sequence of prey captures when mixture of prey was presented: These data were used to determine if the predator showed any preference among prey types. This was done by first ranking each prey captured with respect to its position in the overall sequence relative to the first prey caught (i.e. first prey captured, rank $=1$; second, rank $=2 ; \ldots ; x$ prey captured, rank $=x ; x=20$ maximum), and then comparing the mean rank for each prey type using an Analysis of

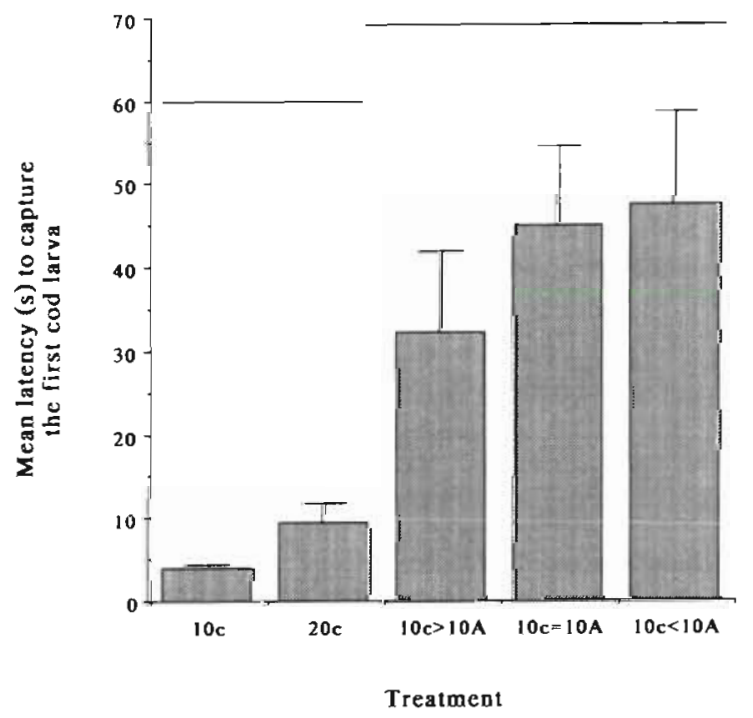

Fig. 1. Gasterosteus aculeatus preying on Gadus morhua. Mean (+ $1 \mathrm{SE}$ ) latency (in seconds) until a stickleback captured its first cod larva. (Treatment: $10 \mathrm{c}$ and $20 \mathrm{c}=10$ and 20 cod larvae presented alone, respectively; $10 \mathrm{c}>10 \mathrm{~A}, 10 \mathrm{c}=10 \mathrm{~A}$ and $10 \mathrm{c}<10 \mathrm{~A}=10 \mathrm{cod}$ larvae presented with 10 Artemia salina smaller, equal and larger in size than the cod larvae, respectively.) Means with a solid line above them are not significantly different

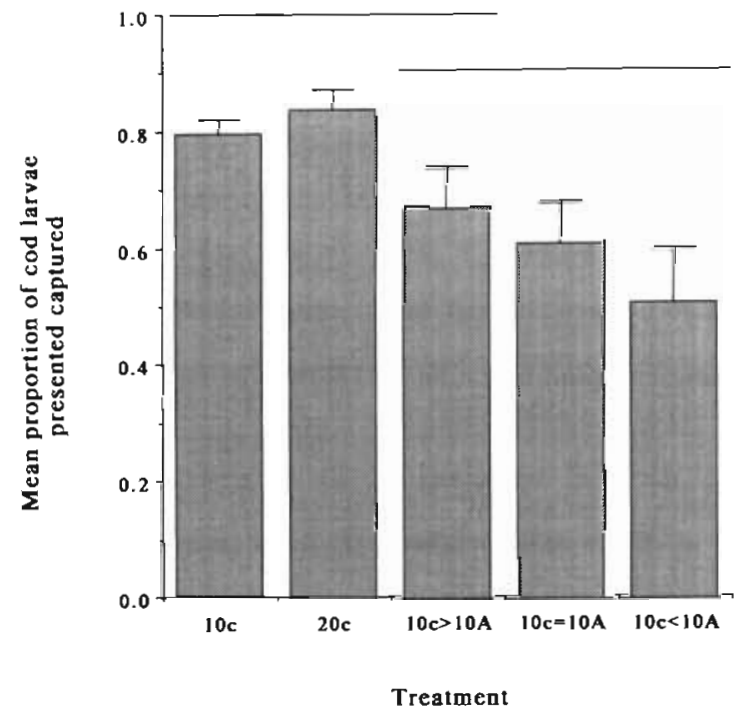

Fig. 2. Gasterosteus aculeatus preying on Gadus morhua. Mean (+ $1 \mathrm{SE}$ ) proportion of cod larvae originally introduced into the test tank that were captured by a stickleback over the course of an experimental trial. (Treatment: as in Fig. 1.) Means with a solid line above them are not significantly different

Variance (GLM Procedure; SAS 1988). No significant difference in mean rank between prey types would indicate no preference by the predator. A significantly lower mean rank for one prey type would indicate consistent selection by the predator for that prey type earlier during a feeding bout, and should, therefore, reflect a preference for that prey.

\section{RESULTS}

\section{Expt 1}

It took sticklebacks significantly $(F=12.6, \mathrm{df}=4,34$, $\mathrm{p}=0.0001$ ) longer to catch a cod larvae in the presence of Artemia. This was true regardless of the size of Artemia presented relative to that of the cod larvae (Fig, 1). There was also a significant $(F=5.42$, df $=$ $4,34, p=0.002$ ) treatment effect on the proportion of cod larvae introduced that were captured over the course of a feeding bout. Significantly fewer larvae were captured when in the presence of Artemia which were larger or equal in length to the cod larvae (Fig. 2).

Regardless of whether cod larvae were presented alone or in the presence of Artemia, predator foraging success (i.e. no. of captures per no. of attacks) on larvae was $100 \%$. Predator foraging success on Artemia was also $100 \%$, regardless of the size of the Artemia presented. 


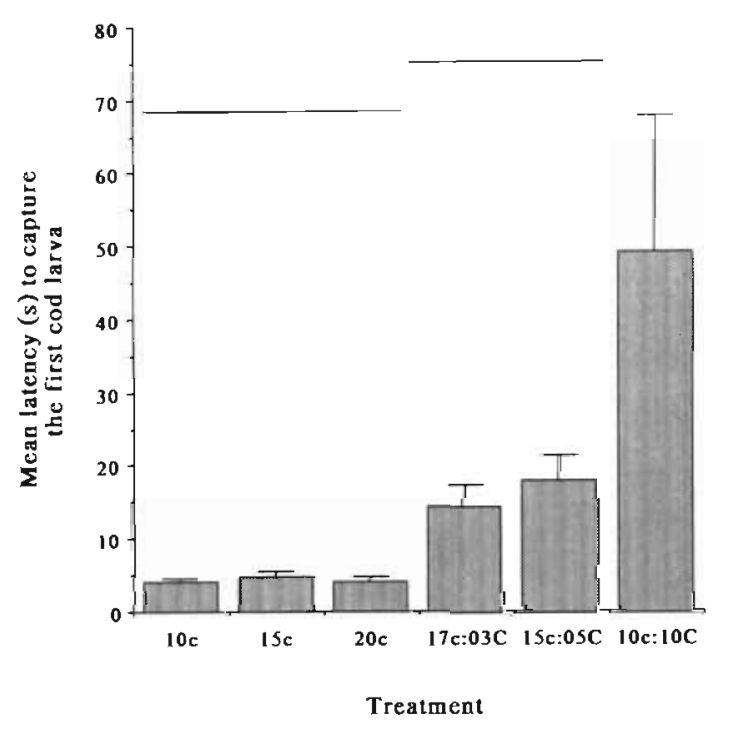

Fig. 3. Gasterosteus aculeatus preying on Gadus morhua. Mean (+ 1 SE) latency ( $s$ ) until a stickleback captured its first cod larva. (Treatment: $10 \mathrm{c}, 15 \mathrm{c}$ and $20 \mathrm{c}=10,15$ and $20 \mathrm{cod}$ larvae presented alone, respectively; $10 \mathrm{c}: 10 \mathrm{C}, 15 \mathrm{c}: 05 \mathrm{C}$ and $17 \mathrm{c}: 03 \mathrm{C}=10,15$ and 17 cod larvae presented with 10,5 and 3 adult Calanus finmarchicus, respectively.) Means with a solid line above them are not significantly different

In mixed presentations, Artemia appeared to be the preferred prey, as the mean rank in the sequence of prey captures for Artemia was significantly lower than that for cod larvae, indicating that Artemia were captured significantly earlier during a foraging bout. This was true when Artemia were smaller $(F=13.19$, df $=1,126, \mathrm{p}=0.0004$, mean rank Artemia $=6.5, \mathrm{cod}$ larvae $=8.9)$, equal $(F=32.98, \mathrm{df}=1,113, \mathrm{p}=0.0001$, mean rank Artemia $=5.5$, cod larvae $=9.8$ ) and larger $(F=68.11$, df $=1,140, \mathrm{p}=0.0001$, mean rank Artemia $=5.8$, cod larvae $=11.6$ ) in size than the cod larvae. There was no significant difference in this pattern of prey capture among the different experimental fish used (Treatment 10c $>10 \mathrm{~A}: F=1.68$, df $=9,126$, $\mathrm{p}=0.1$; Treatment $10 \mathrm{c}=10 \mathrm{~A}: F=1.01, \mathrm{df}=9,113$, $\mathrm{p}=0.4353$; Treatment 10c $<10 \mathrm{~A}: F=1.35, \mathrm{df}=9,140$, $\mathrm{p}=0.2166)$.

\section{Expt 2}

The presence of adult Calanus significantiy increased the time until a stickleback captured its first cod larva $(F=19.41$, df $=5,31, \mathrm{p}=0.0001)$. This was true when the ratio of larvae to Calanus was $1: 1,3: 1$ and 5.6:1 (Fig. 3). Both the presence and number of Calanus present had a significant effect on the proportion of cod larvae captured by the predator $(F=11.42$, $\mathrm{df}=5,31, \mathrm{p}=0.0001$ ). Significantly fewer larvae were captured when in the presence of an equal number of Calanus or when the ratio of larvae to Calanus was 3:1, as compared to that captured when the larvae were presented alone or when the ratio of larvae to Calanus was 5.6:1 (Fig. 4).

As in Expt 1, regardless of whether cod larvae were presented alone or in the presence of Calanus, stickleback foraging success on larvae was $100 \%$ (i.e. all attacks led to a capture). In contrast, predator foraging success on the Calanus was lower, averaging ( $\pm 1 \mathrm{SE}$ ) only $40 \%( \pm 4.0)$. The ratio of Calanus to cod larvae had no significant effect on predator foraging success on the Calanus $(F=1.4$, $\mathrm{df}=2,15, \mathrm{p}=0.28$ ).

The mean rank for Calanus in the sequence of prey captures was significantly lower than that for cod larvae, regardless of the ratio of larvae to Calanus presented (Treatment 10c:10C: $F=23.65$, df $=1,89$, $p=0.0001$, mean rank Calanus $=3.6$, cod larvae $=6.3$; Treatment 15c:05C: $F=10.28$, df $=1,111, p=0.0018$, mean rank Calanus $=4.3$, cod larvae $=6.3$; Treatment $17 \mathrm{c}: 03 \mathrm{C}: F=28.25 \mathrm{df}=1,152, \mathrm{p}=0.0001$, mean rank Calanus $=3.4$, cod larvae $=8.3$ ). These results indicate that stickleback tended to capture Calanus prior to cod larvae, indicating a preference for the Calanus. There was no significant difference in this pattern of prey captures among the different fish when an equal number of cod and Calanus were presented $(F=1.34$, df $=$ $11,89, p=0.2155)$ or when the ratio of larvae to Calanus was $3: 1(F=1.32$, df $=11,111, p=0.2201)$. However, individual sticklebacks did differ in their

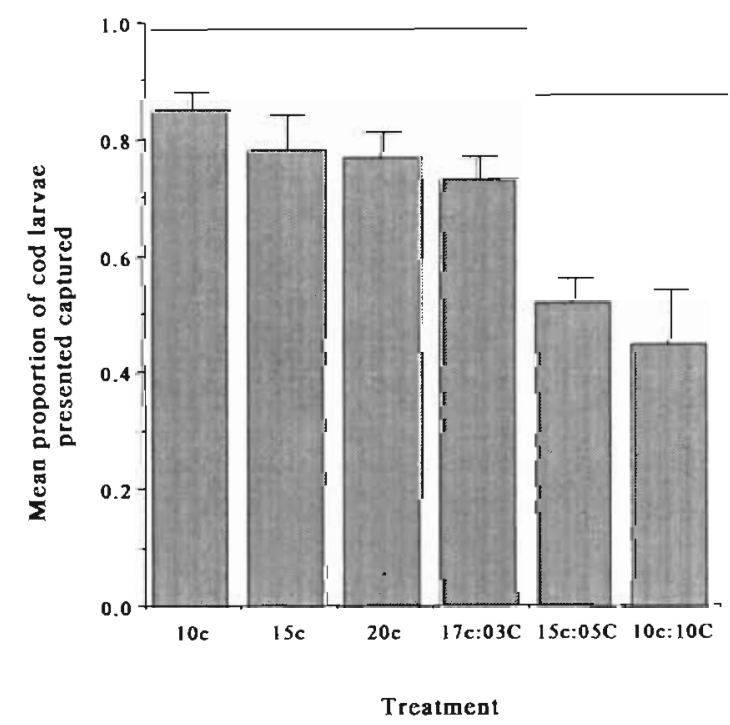

Fig. 4. Gasterosteus aculeatus preying on Gadus morhua. Mean ( $1 \mathrm{SE}$ ) proportion of cod larvae originally introduced into the test tank that were captured by a stickleback over the course of an experimental trial. (Treatment: as in Fig. 3.) Means with a solid line above them are not significantly different 
pattern of prey selection when the ratio of cod larvae to Calanus was 5.6:1 $(F=1.99$, $\mathrm{df}=11.152, \mathrm{p}=0.0326)$.

\section{Comparison of Artemia and Calanus as alternative prey}

When sticklebacks were offered cod larvae and an equal number of alternative prey which were equal in size to the larvae, significantly fewer larvae were captured $(F=9.65, \mathrm{df}=5.37, \mathrm{p}=0.0001)$ and it took the sticklebacks significantly longer to capture a larva $(F=$ 15.92, $\mathrm{df}=5,37, \mathrm{p}=0.0001$ ) as compared to when larvae were presented alone. This was true regardless of whether Artemia or Calanus was the alternative prey present. Further, there was no significant difference in mean latency until a cod larva was captured (Treatment: $\bar{x} \pm 1 \mathrm{SE}_{;} 10 \mathrm{c}: 10 \mathrm{C}: 49.3 \pm 18.3 ; 10 \mathrm{c}=10 \mathrm{~A}: 30.4 \pm$ $5.8)$ or in the mean proportion of cod larvae captured (10c:10C: $0.45 \pm 0.09 ; 10 \mathrm{c}=10 \mathrm{~A}: 0.5 \pm 0.05$ ) between treatments using Artemia or Calanus as the alternative prey.

\section{DISCUSSION}

In this study, size of alternative prey was shown to significantly influence the risk of predation to larval cod from a visually feeding planktivorous fish. The proportion of cod larvae captured was significantly reduced when zooplankton of equal or larger body size were also present. A reduced risk of predation to fish larvae has also been demonstrated when in the presence of alternative prey smaller than the larvae (KeanHowie et al. 1988, Margulies 1990). However, in these studies protection to the larvae was only evident when the number of alternative prey relative to that of the larvae was high. Protection to the larvae was attributed to interference with the predators foraging by the presence of such large numbers of alternative prey, In contrast to these earlier results, our study demonstrated a significant reduction in the risk of predation to cod larvae in the presence of alternative prey that were equal or larger in size than the larvae. This was true even at a ratio as low as 1 zooplankter to every 3 larvae. Further, this protection appears to be the result of selection by the predator of the alternative prey over the larvae. Overall, our results are consistent with the findings of various freshwater studies investigating predator-prey relationships between planktivorous fish and zooplankton demonstrating a preference and selection for larger-bodied prey (Brooks \& Dodson 1965, Werner \& Hall 1974, O'Brien 1979, O'Brien et al. 1985). Taken together, these results suggest that fish larvae should gain some level of protection from visu- ally foraging planktivorous fish when alternative prey of equal or larger size are present in the planktonic community.

It is unclear as to the extent to which our results are transferable to the field. For example, field studies report a wide range in the abundance of cod larvae and various zooplankters, ranging 1 to 2 orders of magnitude lower and higher than that used in our study (e.g. Solemdal \& Ellertsen 1984, Economou 1987 , MacKenzie et al. 1990). Therefore, under certain conditions, field prey levels may be considered too low for predators to commonly encounter a number of different prey types simultaneously. However, field collections provide no, or little, information on the 'microdistribution' of planktonic organisms relative to each other within the volume of water sampled. As such, due to various biotic (e.g. behavioural) and abiotic (e.g. current) factors, organisms may actually be in close enough proximity to offer predators a choice among prey types. In our study, the risk of predation to cod larvae was significantly reduced in the presence of an equal number of Calanus, as well as at a ratio as low as 1 Calanus to every 3 cod larvae. Field results, where spatial overlap between cod larvae and adult $C$. finmarchicus has been reported (Skreslet 1989), show the ratio of C. finmarchicus to cod larvae to be greater than $1: 1$, averaging $7: 1$ for $C$. finmarchicus of the size used in our study. Based on our results, these field data suggest that the potential for a reduced risk of predation to cod larvae because of the presence of this alternative prey could exist in the field.

Body size alone may explain preference by the predator for alternative prey larger than the cod larvae. However, factors other than body size may have played a role in the protection evident to larvae when alternative prey of similar size where present, as well as the preference shown for smaller Artemia by the predator. Factors which we could not control, such as movement, pigmentation and evasiveness, have all been shown to significantly influence prey selection by planktivorous fish (Ware 1973, O'Brien 1979, Vinyard 1980, O'Brien et al. 1985). Prey movement has been shown to affect prey choice by three-spined stickleback (Ibrahim \& Huntingford 1989). Therefore, differences in the amount and/or type of movement(s) demonstrated by Artemia and Calanus as compared to cod larvae could have led to the observed selection for alternative prey equal or smaller in size than the larvae. The 3 prey types used in our study did not appear to differ significantly in their pigmentation. However, from our experiments, it is impossible to eliminate the possibility that Artemia and Calanus were selected over the cod larvae because of some pigmentation differences detected by the predator. Finally, given that stickleback foraging success on Artemia and cod larvae was $100 \%$ regardless of 
Artemia body size, a difference in evasiveness between these 2 prey types would seem unlikely as the reason for the observed preference for the Artemia. In contrast, copepods are generally considered to be good at evading predators (O'Brien 1979, Coughlin \& Strickler 1990), and our results on predator foraging success on Calanus would support such a conclusion. In our study, Calanus was much more difficult for the stickleback to capture than were cod larvae. As such, one might have expected cod larvae of equal size to have been the preferred prey. However, a comparison of the potential energetic returns from consuming a Calanus of the size used in this study [1.73 cal (prey item) ${ }^{-1}$, unpubl. data] to that from consuming a similar sized cod larva [0.43 cal (prey item $)^{-1}$, unpubl. data] indicates that the capture of a Calanus represented a greater reward. Therefore, Calanus may have been preferred over the larvae because even though 2.5 times the effort was required to capture a Calanus (i.e. foraging success $=$ no. of captures per no. of attacks on Calanus $=40$ vs $100 \%$ on cod larvae), for each capture the stickleback received 4 times the energetic reward. However, additional experiments examining the actual energetic costs incurred by the stickleback when capturing a Calanus vs a cod larva are needed to definitively address this question.

Studies investigating factors affecting prey choice or risk to predation among planktivores and their prey are difficult to conduct in the field. While some wild zooplankters can be maintained in the laboratory, others are difficult and the availability of most is seasonal. In this study, the risk of predation to cod larvae was significantly reduced when in the presence of an equal number of Calanus or Artemia of equal size as the larvae. Also, there was no significant difference in the level of protection offered cod larvae by the presence of either of these alternative prey types. Given these results and the fact that Artemia are commercially available and easy to maintain in the laboratory, Artemia may provide a suitable representative zooplankter for certain studies addressing questions on the effects of alternative prey on prey selection by, and risk of predation from, planktivores.

Various studies examining factors influencing the risk of predation to fish larvae have concluded that larval vulnerability to predation decreases with increasing larval size and age (Bailey \& Batty 1984, Blaxter 1986, Blaxter \& Pickett 1988, Miller et al. 1988, Fuiman 1989, Margulies 1990). This conclusion, often referred to as the 'bigger-is-better' hypothesis, is primarily based on the analyses of changes in predation risk to fish larvae within a single cohort or size class. However, in nature predators are typically confronted simultaneously with larvae of various sizes and ages. Therefore, recent studies by Litvak \& Leggett (1992) and Pepin et al. (1992) have experimentally questioned the generality of the bigger-is-better concept on the basis of the validity of examining changes in predation risk to fish larvae based only on a within-cohort comparison. Results from both these studies showed that while the risk of predation to larvae did decrease with increasing size/age within a cohort, this was not the case when predators were simultaneously offered a choice of larvae from different cohorts. In this latter case, the larger/older larvae were preyed upon much more heavily than the smaller ones. These results are similar to our findings where alternative prey equal or larger in size than the cod larvae were preferred and the risk of predation to the smaller larvae was significantly reduced. Taken together, these results suggest that bigger may not always be better with respect to reducing the risk of predation to larval fish within the planktonic community.

Although predation is considered a major source of mortality in larval fishes (Hunter 1981, 1984, Bailey \& Houde 1989), survival depends not only on larvae avoiding being eaten, but also on getting sufficient food. Following yolk-absorption, fish larvae go through a critical period of first feeding (i.e. transition to exogenous feeding) during which an insufficient intake of food results in death. As such, a temporal and spatial overlap between first feeding larvae and a sufficient number of appropriate-sized prey is important for larval survival. This concept of overlap has been termed the 'match-mismatch' hypothesis, a match occurring in years in which the various environmental factors affecting the timing of reproduction in both fish and various zooplankters produce an overlap between the larvae and their prey (i.e. early life stages of the zooplankters) (e.g. Ellertsen et al. 1989). However, a match should also produce a temporal overlap between fish larvae and spawning adult zooplankters. Based on results from our study, such an overlap should further enhance the survival of the fish larvae by reducing their risk to predation, given of course that the adult zooplankters are of an appropriate size and that a spatial overlap between larvae and these zooplankters also occurs. Such an overlap has been reported for cod larvae and adult Calanus finmarchicus (Skreslet 1989). Further studies are needed to investigate the generality of such temporal and spatial overlaps between fish larvae, their prey and adult zooplankters, and the relative importance of each to larval survival.

Acknowledgements. We thank G. Brown, J. Morgan, P. J. Williams, and 3 anonymous reviewers for their helpful comments on this manuscript. This research was supported by funding from OPEN - the Ocean Production Enhancement Network - one of the 15 Networks of the Centres of Excellence supported by the Government of Canada. This is Ocean Sciences Centre contribution \# 218. 


\section{LITERATURE CITED}

Bailey, K. M., Batty, R. S. (1984). Laboratory study of predation by Aurelia aurita on larvae of cod, flounder, plaice and herring: development and vulnerability to capture. Mar. Biol. 83: 287-291

Bailey, K. M. Houde, E. D. (1989). Predation on eggs and larvae of marine fishes and the recruitment problem. Adv mar. Biol. 25: 1-83

Bailey, K. M., Yen, J. (1983). Predation by a carnivorous marine copepod, Euchaeta elongata, Esterly, on eggs and larvae of the Pacific hake, Merluccins productus. J. Plankton Res. 5: 71-82

Blaxter, J. H. S. (1986). Development of sense organs and behaviour of teleost larvae with special reference to feeding and predator avoidance. Trans. Am. Fish. Soc. 115: 98-114

Blaxter, J. H. S., Pickett, D. (1988). Age-specific vulnerability of Pacific sardine, Sardinops sagox, larvae to predation by northern anchovy. Fish. Bull. U.S. 86: 163-167

Brooks, J. L., Dodson, S. I. (1965). Predation, body size, and composition of plankton. Science 150:28-35

Coughlin, D. J., Strickler, J. R. (1990). Zooplankton capture by a coral reef fish: an adaptive response to evasive prey. Environ. Biol. Fish. 29: 35-42

Delbeek, J. C., Williams, D. D. (1988). Feeding selectivity of four species of sympatric stickleback in brackish-water habitats in eastern Canada. J. Fish. Biol. 32: 41-62

Economou, A. N. (1987). Ecology of survival in some gadoid larvae of the northern North Sea. Environ. Biol. Fish. 19: $241-260$

Ellertsen, B., Fossum, P., Solemdal, P., Sundby, S. (1989). Relation between temperature and survival of eggs and first-feeding larvae of northeast Arctic cod (Gadus morhua L.). Rapp. P.-v. Réun. Cons. int. Explor. Mer 191: 209-219

Fuiman, L. A. (1989). Vulnerability of Atlantic herring larvae to predation by yearling herring. Mar. Ecol. Prog. Ser. 51: $291-299$

Fuiman, L. A., Gamble, J. C. (1988). Predation by Atlantic herring, sprat, and sandeels on herring larvae in large enclosures. Mar. Ecol. Prog. Ser. 44: 1-6

Hunter, J. R. (1981). Feeding ecology and predation of marine fish larvae. In: Lasker, R. (ed.) Marine fish larvae, morphology, ecology and relation to fisheries. Univ, of Washington Press, Seattle, p. 287-330

Hunter, J. R. (1984). Inferences regarding predation on early life stages of cod and other fishes. In: Dahl, E., Danielssen, D. S., Moksness, E., Solemdal, P. (eds.) The propagation of cod Gadus morhua L. Flodevigen rapportser 1, Arendal, p. $533-562$

Ibrahim, A. A., Huntingford, F. A. (1989). The role of visual cues in prey selection in three-spined sticklebacks (Gasterosteus aculeatus). Ethology 81: 265-272

Kean-Howie, J. C., Pearre, S., Dickie, L. M. (1988). Experimental predation by sticklebacks on larval mackerel and protection of fish larvae by zooplankton alternative prey. J. exp. mar. Biol. Ecol. 124: 239-259

Lemmetyinen, R., Mankki, J. (1975). The three-spined stickleback (Gasterosteus aculeatus) in the food chains of the northern Baltic. Merentutkimuslaitoksen Julk. Havsforskningsinst. Skr. 239: 155-161

Litvak, M. K, Leggett, W C. (1992). Age and size-selective predation on larval fishes: the bigger-is-better hypothesis

This article was submitted to the editor revisited. Mar. Ecol. Prog. Ser. 81: 13-24

MacKenzie, B. R., Leggett, W. C., Peters, R. H. (1990). Estimating larval fish ingestion rates: can laboratory derived values be reliably extrapolated to the wild? Mar. Ecol. Prog. Ser. 67: 209-225

Margulies, D. (1990). Vulnerability of larval white perch Morone americana, to fish predation. Environ. Biol. Fish. 27: $187-200$

Miller, T. J., Crowder, L, B., Rice, J. A., Marschall, E. A (1988). Larval size and recruitment mechanisms in fishes: towards a conceptual framework. Can. J. Fish. Aquat. Sci. 45: $1657-1670$

Montgomery, D. L. (1991). Design and analysis of experiments, 3rd edn. John Wiley \& Sons, New York, p. $128-140$

O'Brien, W. J. (1979). The predator-prey interaction of planktivorous fish and zooplankton. A.m. Scient. 67: 572-581

O'Brien, W. J., Evans, B., Luecke, C. (1985). Apparent size choice of zooplankton by planktivorous sunfish: exceptions to the rule. Environ. Biol. Fish. 13: 225-233

O'Brien, W. J., Slade, N. A., Vinyard, G. L. (1976). Apparent size as a determinant of prey selection by bluegill sunfish (Lepomis macrochirus). Ecology 57: 1304-1310

Pepin, P. (1987). Influence of alternative prey abundance on pelagic fish predation of larval fish: a model. Can. J. Fish. Aquat. Sci. 44: 222-227

Pepin, P., Koslow, J. A., Pearre, S. (1988). Laboratory study of foraging by Atlantic mackerel, Scomber scombrus, on natural zooplankton assemblages. Can. J. Fish. Aquat. Sci. 45: 879-887

Pepin, P., Shears, T. H., de Lafontaine, Y. (1992). Significance of body size to the interaction between larval fish (Mallotus villosus) and a vertebrate predator (Gasterosteus aculeatus). Mar. Ecol. Prog. Ser. 81: 1-12

SAS Institute (1988). SAS/STAT user's guide, release 6.03 edn. SAS Institute, Inc., Cary, NC

Skreslet, S. (1989). Spatial match and mismatch between larvae of cod (Gadus morhua L.) and their principle prey, nauplii of Calanus finmarchicus (Gunnerus). Rapp. P.-v. Réun. Cons. int. Explor. Mer 191: 258-263

Solemdal, P., Ellertsen, B. (1984). Sampling fish larvae with large pumps; quantitative and qualitative comparison with traditional gear. In: Dahl, E., Danielssen, D. S. Moksness, E., Solemdal, P. (eds.) The propagation of cod Gadus morhua L. Flodevigen rapportser 1, Arendal, p. 335-363

Vinyard, G. L. (1980). Differential prey vulnerability and predator selectivity: effects of evasive prey on bluegill (Lepomis macrochirus) and pumpkinseed (L. gibbosus) predation. Can. J. Fish. Aquat. Sci. 37: 2294-2299

Visser, M. (1982). Prey selection by the three-spined stickleback (Gasterosteus aculeatus). Oecologia 55: 395-402

Ware, D. M. (1973). Risk of epibenthic prey to predation by rainbow trout (Salmo gairdneri). J. Fish. Res. Bd Can. 30: $787-797$

Werner, E. E., Hall, D. J. (1974). Optimal foraging and the size selection of prey by the bluegill sunfish (Lepomis macrochirus). Ecology 55: 1042-1052

Wootton, R. J. (1984). A functional biology of sticklebacks. University of California Press, Berkeley

Zaret, T., Kerfoot, W. C. (1975). Fish predation of Bosmina longirostris: body-size selection versus visibility selection. Ecology 56: 232-237

Manuscript first received: January 28, 1993

Revised version accepted: June 8, 1993 